NASA/CR-1998-206607

ND.

Power, Propulsion, and Communications for Microspacecraft Missions

W.A. de Groot, T.M. Maloney, and M.J. Vanderaar

NYMA, Inc., Brook Park, Ohio

Prepared for the

COSPAR Colloquium on Scientific Microsatellites

cosponsored by the Committee on Space Research, International Academy

of Astronautics, and the National Science Council (NSC)

Tainan, Taiwan, ROC, December 14-17, 1997

Prepared under Contract NAS3-27186

National Aeronautics and

Space Administration

Lewis Research Center 
Available from

NASA Center for Aerospace Information 800 Elkridge Landing Road

Linthicum Heights, MD 21090-2934

Price Code: A03
National Technical Information Service 5287 Port Royal Road Springfield, VA 22100 


\title{
POWER, PROPULSION, AND COMMUNICATIONS FOR MICROSPACECRAFT MISSIONS
}

\author{
W. A. de Groot, T. M. Maloney, and M. J. Vanderaar \\ Nyma Inc., 2001 Aerospace Parkway \\ Brook Park, OH 44142, USA
}

\begin{abstract}
The development of small sized, low weight spacecraft should lead to reduced scientific mission costs by lowering fabrication and launch costs. An order of magnitude reduction in spacecraft size can be obtained by miniaturizing components. Additional reductions in spacecraft weight, size, and cost can be obtained by utilizing the synergy that exists between different spacecraft systems. The state-of-the-art of three major systems, spacecraft power, propulsion, and communications is discussed. Potential strategies to exploit the synergy between these systems and/or the payload are identified. Benefits of several of these synergies are discussed.
\end{abstract}

\section{INTRODUCTION}

In an era of continually shrinking budgets it is prudent to investigate means of reducing spacecraft mission costs. These costs can roughly be divided among three categories: $a$. spacecraft cost (mission payload and spacecraft bus); b. launch costs; c. mission operations and data analysis cost. Reducing the spacecraft size and weight impacts both spacecraft and launch costs. Proposed spacecraft classifications by power and weight are indicated in Figure 1. As shown in Figure 1, most conventional spacecraft have an energy density of approximately $1 \mathrm{~W} / \mathrm{kg}$ (dashed line). Microspacecraft are classified as spacecraft smaller than approximately 100 $\mathrm{kg}$ with power less then $100 \mathrm{~W}$. Few existing spacecraft in this category are equipped with propulsion systems.

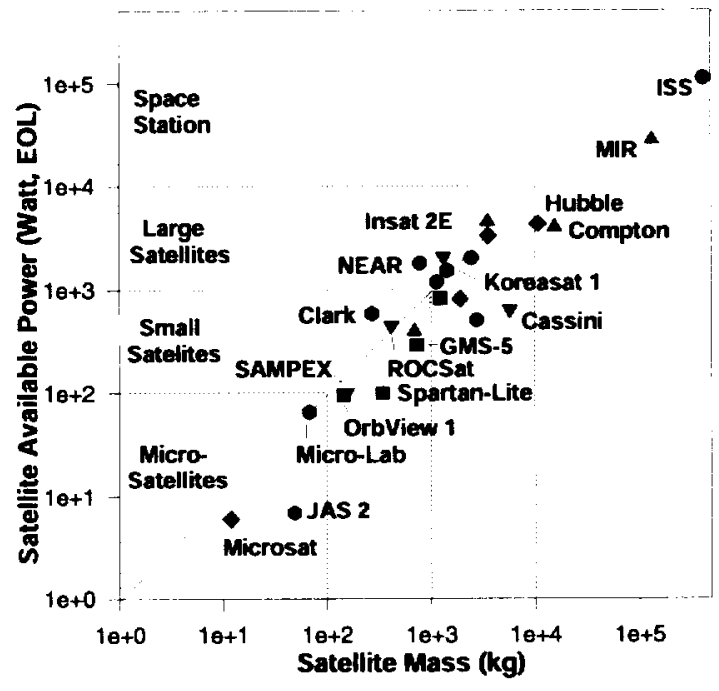

Figure 1. Spacecraft Classification

To reduce costs and risk associated with single large spacecraft, the development of microspacecraft has been proposed. To meet the mass and volume reductions targeted, radical changes in component technology are needed. Janson (1994) provides an approach towards obtaining microcomponents with micro-electromechanical systems (MEMS) technology and describes the potential MEMS advantage of subsystems integration as a result of the silicon base material properties. His bold vision of an armada of sub-kg spacecraft, composed out of a threedimensional stack of silicon wafers, and lofted in orbit with a single launch vehicle, is a challenging goal for future spacecraft builders. The microsizing of propulsion systems presents a tremendous challenge. One scenario used to circumvent this problem is the use of a "mothership" that brings 
the microspacecraft to the desired orbits. The "mothership" will have the propulsion system needed to deploy the microspacecraft and have the high data rate communications capability lacking on the microspacecraft. Although it is very likely that this vision will, at sometime in the future become a reality, technical hurdles and limitations in R\&D funding will delay the realization.

For many smaller countries and for scientific institutions with spaceflight aspirations but limited budget, an alternative, low cost approach towards miniaturization could be followed to obtain significant mass and cost savings. Such a strategy, which includes incremental reduction in size and weight of spacecraft components, calls for more efficiently designed satellites, which are smaller in size and budget. Several subsystems, such as sensors, electronics, and communications lend themselves readily for miniaturizing. One approach to reducing propulsion system volume and mass is to leverage multi-functionality of spacecraft systems. An example of such multifunctionality was proposed by McElroy (1994). In this proposal, propulsion, power, satellite structure and tankage were integrated to provide maximum performance for a minimum in system weight and volume. In this scenario, the consumables (water) doubled as energy storage medium.

This paper describes the current state of the art in the three disciplines of propulsion, power, and communications. A number of possible integration options for these three subsystems that could reduce satellite mass and volume, while retaining mission capabilities, are reviewed. Both satellite bus subsystems and payload instrumentation can be integrated with any of the satellite subsystems. However, that option depends on the type of instrumentation used.

\section{POWER-ENERGY CONVERSION AND STORAGE TECHNOLOGY}

A number of different electrical power systems can be assessed for application to spacecraft payload power. In addition to solar cells, non-rechargeable (primary) and rechargeable (secondary) batteries, fuel cells, semi-cells, flywheels, and capacitors are candidate components for integrated power systems. Microwave and laser beamed power systems can also be considered subject to severe operational constraints as can nuclear power sources. Future spacecraft will require smaller and cheaper components than those that are presently in use so the space industry as a whole will benefit greatly from the ongoing worldwide efforts in electric vehicle component development and from the development of new military power systems. A comprehensive survey of energy source technologies is presented which includes state-of-the-art performance parameters as well as performance parameters projected to be achieved in the year 2000 .

It is essential that all the components of candidate power systems are included in the assessments and comparisons among those systems. The ancillary components are especially important for space power systems where harsh environments are encountered. The nickel-hydrogen battery system designed for the International Space Station, for example, has an overall specific energy of $6.5 \mathrm{Wh} / \mathrm{kg}$ even though the batteries are nominally rated as $50 \mathrm{Wh} / \mathrm{kg}$. In addition to the total power system mass and volume, the availability, reliability, environmental compatibility, and cost must be addressed during spacecraft design. An excellent survey of the current and projected electrical power system technologies was reported by Power Computing Solutions, Inc. (1997)

Solar Cells. Solar cells are a major component of virtually every spacecraft power system. There are three main types or classes of solar cells under production today, thin film, single junction and multiple junction. Solar cell integration with a specific spacecraft requires that the individual cells be mounted on a suitable support structure with the ability to cool the solar cell modules and/or to shield the solar cells from a space plasma environment. In general, the multi-junction cells are most 
efficient, reported as $23 \%$ compared to $15 \%$ for single junction and $10 \%$ for thin film. But the multi-junction cells are also the most expensive, and most difficult to handle and install. While each type of solar cell has already been flight demonstrated on solar electric unmanned aerial vehicle (UAV) platforms, the multi-junction cells are generally deemed uneconomical. Even though the lowest cost thin film cells have relatively low efficiencies, they may be the most attractive spacecraft system option if a lightweight mounting structure is used (PCS 1997).

Batteries. A myriad of primary and secondary batteries are available today ranging from the low cost primary commercial alkaline batteries that are used in ordinary flashlights to the higher cost lithium and nickel based batteries. Excellent performance has already been demonstrated in primary battery systems and no further advancements in performance are anticipated in the near future since no significant development programs are underway to improve the primary battery performance. In contrast, there are significant ongoing secondary battery development programs that will advance the state-of-the-art for leadacid, $\mathrm{Ni}-\mathrm{Cd}, \mathrm{NiH}_{2}, \mathrm{Ni}-\mathrm{MH}$, and several different lithium based designs.

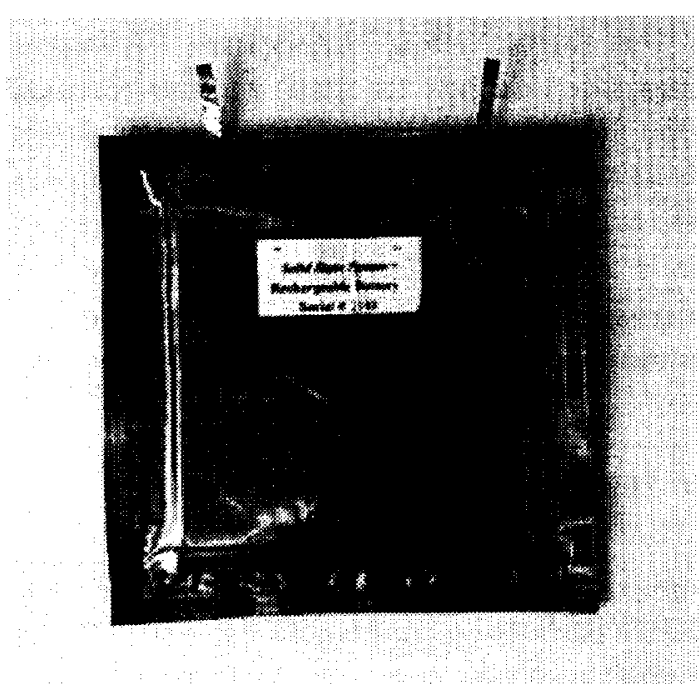

Figure 1. Advanced Lithium-Ion Battery
Table 1. United States Advanced Battery Consortium Battery Goals

\begin{tabular}{|l|l|l|}
\hline & $\begin{array}{l}\text { Mid- } \\
\text { Term } \\
(1995)\end{array}$ & $\begin{array}{l}\text { Long- } \\
\text { Term } \\
(1998)\end{array}$ \\
\hline Specific Energy (Wh/kg) & $>80$ & 200 \\
\hline Energy Density (Wh/l) & $>135$ & $>300$ \\
\hline Peak Specific Power (W/kg) & 150 & 400 \\
\hline Power Density (W/) & 250 & 600 \\
\hline Cycle Life (cycles) & 600 & 1000 \\
\hline Calendar Life (yrs.) & 5 & 10 \\
\hline Efficiency (\%) & 75 & 75 \\
\hline Recharge Time (hrs.) & $<6$ & $3-6$ \\
\hline Fast Recharge Time (hrs.) & 0.25 & 0.25 \\
\hline 1 hr Continuous Discharge & 75 & 75 \\
\hline $\begin{array}{l}\text { Power and Capacity } \\
\text { Degradation (\%) }\end{array}$ & 20 & 20 \\
\hline Operating Environment ( $\left.{ }^{\circ} \mathrm{C}\right)$ & $-30-60$ & $-40-85$ \\
\hline Cost (US\$/kWh) & $<150$ & $<100$ \\
\hline
\end{tabular}

The rechargeable lithium batteries exhibit the most promise for superior energy density and specific energy but the nickel based chemistries are still considered the baseline battery systems for space missions today. This may change before the turn of the century if the goals of the major battery development programs are achieved. One of the most significant development programs is being conducted by the United Sates Advanced Battery Consortium (USABC). 
While the long term goals of the USABC shown in Table 3 were targeted for 1998, it is reasonable to consider those battery level performance targets as the upper limit for secondary batteries for the year 2000. The system level performance will obviously be less than the cell level performance. An example of a state-of-the-art flexible lithium-ion battery is shown in Figure 1. A comprehensive discussion of secondary battery technology characteristics is presented by Pellerin (1996).

Fuel Cells. Non-regenerative fuel cells were first used as a primary on-board electrical power source for the NASA Gemini Program in the 1960's and today, the Space Shuttle Orbiter extracts all needed electricity from fuel cells. In addition to the NASA program that was initiated in early 1997 to investigate implementing new fuel cells on the Space Shuttle (Warshay 1997), there is approximately $\$ 200 \mathrm{M}$ per year being invested worldwide to develop fuel cell systems for military and commercial stationary power and transportation applications. As a result of these programs, the state of fuel cell technology will advance significantly in the next three years. For the short charge/discharge power system duty cycles prevalent in LEO spacecraft and for the large charge/discharge time ratios prevalent in GEO (as well as LEO) spacecraft, secondary battery systems have been better suited than fuel cells. If the spacecraft power demands are increased or if the discharge time period of the non-photovoltaic power source increases to more than several hours, fuel cell systems would be a better power system options than batteries. For a $5 \mathrm{~kW}$ regenerative fuel cell system with twelve hour charge and discharge times, over $230 \mathrm{Wh} / \mathrm{kg}$ can be achieved today and over $500 \mathrm{Wh} / \mathrm{kg}$ is projected to be achieved in the year 2001 (PCS 1997).

Flywheels. Several flywheel development programs are being carried out under support from the Partnership for a New Generation of Vehicles (PNGV) where the objective is to integrate flywheels into hybrid vehicles. They can also be considered as a dual purpose energy storage system for future satellites. There are several beneficial features of flywheel systems. Round trip efficiencies of over $90 \%$ have been demonstrated in system tests at Oak Ridge National Laboratory. Flywheels are projected to have long service lives (especially if magnetic bearings are used) and the bearings and power electronics should provide adequate life for the flywheel system. The principal life limiting factor is fatigue of the flywheel rotor although most of the performance predictions in the flywheel literature are based on a life of at least 100,000 deep cycles. The primary risks associated with energy storage in flywheel systems arise from a rotor failure where explosions and/or disintegration could lead to a loss of the spacecraft. Flywheels can be designed for high specific power or for high specific energy. The maximum specific energy achievable is about $400 \mathrm{Wh} / \mathrm{kg}$ and energy densities of over $100 \mathrm{Wh} /$ liter are achievable.

\section{PROPULSION}

Many satellites and spacecraft require a variety of propulsion functions, including orbit insertion, attitude control, station keeping, repositioning, and primary propulsion for planetary spacecraft. As a general rule, chemical propulsion options are for high-thrust, low power applications. Electric propulsion can be used when there is sufficient power available and where low thrust levels are acceptable. With the drive towards smaller spacecraft, miniaturized electric and chemical propulsion systems are gaining attention, especially those with dual use potential. Leveraging spacecraft subsystems for more than one function may make it easier to meet demanding mission scenarios with smaller spacecraft.

Propulsion needs for microspacecraft depend on the launch system used and the mission scenario. The most affordable launch option is to "piggy-back" on an existing launch. In this case, the microspacecraft mission is constrained by, among others, the primary payload's mission and the 
availability of an on-board propulsion system for orbital transfer. More expensive options are small launch vehicles or using getaway special canisters from the Space Shuttle. These missions are less constrained but may still require primary propulsion for orbit transfer and/or orbit insertion. Fine pointing requirements determine the minimum impulse bit specifications of the ACS system. At the same time, scientific requirements may limit the firing frequency during deadbanding, and slew rate required for planetary observations might determine thrust level. A propulsion system that can provide optimum impulse bits satisfying fine pointing, firing frequency limitations, and slew rate needs to be found. In many cases, such a system is not available and a compromise must be made.

A number of low thrust propulsion options are available to carry out specific small missions (de Groot 1997). Volume and mass constraints dictate system selection. Cold gas propulsion is commonly used for tasks where the propulsion requirements are limited and where low cost and system simplicity are decisive factors. Cold gas systems are volumetrically inefficient and the relative high leakage of gaseous storage may make them unsuited for anything but low $\Delta \mathrm{V}$, short duration missions. Monopropellant hydrazine $\left(\mathrm{N}_{2} \mathrm{H}_{4}\right)$ has been the preferred option for orbit insertion of smaller satellites. They have a higher specific impulse (Isp) than cold gas systems but are more costly and complex. Storable bipropellants, utilizing nitrogen tetroxide (NTO) as oxidizer and either monomethylhydrazine (MMH) or $\mathrm{N}_{2} \mathrm{H}_{4}$ as fuel, have been used extensively for orbit insertion of medium to large satellites and primary propulsion for planetary spacecraft. Bipropellant systems operate most effectively at thrust levels which are too high for microspacecraft and can only be considered for some primary thrust functions. Monopropellant $\mathrm{N}_{2} \mathrm{H}_{4}$ and bipropellant MMH/NTO have been used for satellite on-orbit functions, but the trend is now toward electric thruster systems to perform these duties. Resistojets have been used to augment monopropellant performance, and arcjets have recently been utilized for large satellite station keeping. Low power ion and Hall thrusters are being developed for orbit transfer and primary planetary propulsion missions (Myers 1994). Pulsed plasma thrusters are poised to be flight tested for precision on-orbit functions for smaller satellites.

\section{COMMUNICATIONS}

The communications capability (data transmission rate) of a microsatellite is closely related to the amount of power available to the communications electronics as well as the distance over which communications will take place. This is obviously very mission specific. Moreover, the physical size limitation of onboard antennas is also an important issue. In most cases the limit is on the return link from the microsatellite to the ground. In a very rough sense, near-earth microsatellite systems can support rates in excess of 100 kilobits per second (kbps) while deep space missions may have limits on the order of $10 \mathrm{kbps}$.

Increasing these rates and/or decreasing the onboard power consumption to levels appropriate for microsatellite systems can be approached in a number of ways. First, microsatellites can leverage the investment from the burgeoning commercial low power, high performance electronics industry. Much of this technology is commercially available or being developed for mobile applications such as cellular phone, personal communications systems, and wireless networks. In these applications, it is very important to conserve power to increase battery lifetime and thus increase airtime. This is being achieved by advances in devices as well innovative architectures and algorithms.

First, advances in devices include low voltage operation, decreasing feature sizes, and increasing die sizes. However, in general, low power, small feature size electronics can be much more 
susceptible to effects of radiation including latchup and single event upset. In fact, some of these systems are sensitive to the radiation environment at sea level! Currently, researchers at Stanford University and the University of New Mexico are developing a low power standard cell library that is radiation tolerant for both terrestrial and space based applications (Gambles 1997).

Second, microsatellites can trade processing power for RF power. Architectural advances include a new breed of multi-processor, multi-instruction, and special function devices that enable the efficient use of advanced processor architectures and signal processing techniques. There are a number of algorithmic techniques to compress, error control, and modulate digital data which enable more data to be transmitted with less RF power (DC to RF power is roughly only $40 \%$ efficient). The limitation is the amount of DC power required in digital processing to achieve the gains. Also, the same processors used for other on-board purposes can be shared for the communications applications, further reducing the required onboard mass.

For example, NASA has developed lossless signal and image compression techniques that can be used for scientific data (Yeh 1995). In some circumstances lossy compression may also be used if the data integrity can be compromised. In this case, higher compression ratios can be obtained using some of the standard commercial algorithms. As a complement to compression, error correction of the data is of critical importance. The standard method of error correction in space is to use a concatenation of two error correcting codes. This Consultative Committee for Space Data Systems (CCSDS) standard (see Figure 2.) uses an "inner" code based on convolutional coding in conjuction with an optional outer Reed-Solomon block code (CCSDS 1994). This combination provides a powerful error correction capability that reduces the amount of onboard power required to obtain an error-free link. The encoding is normally done on-board the spacecraft, so radiation hardened encoder devices are available. There has also been some recent interest in hardening the decoder devices for receiver space applications. Moreover, new iterative decoding techniques (Berrou 1993) are being developed that provide greater error correction capabilities to within 0.5 $\mathrm{dB}$ of the theoretical limit.

\section{Space Data System Functional Model}

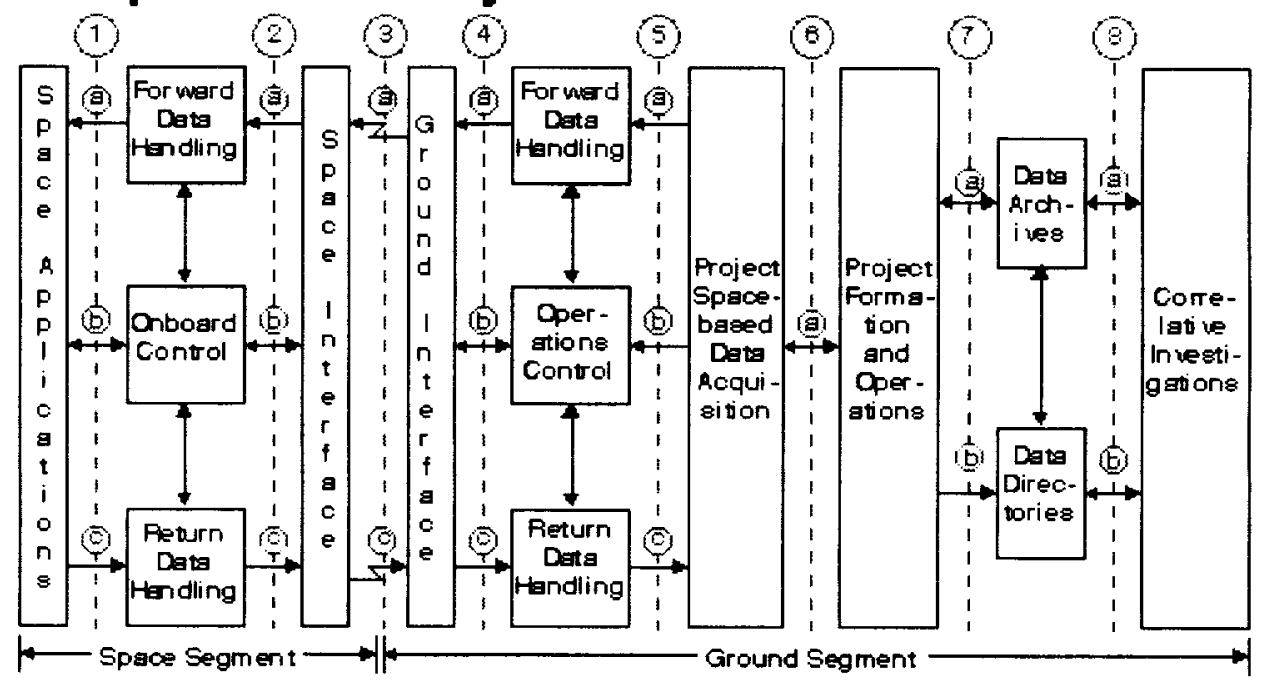

Figure 3: CCSDS Functional Model (from http://www.ccsds.org) 
Third, higher transmission frequencies offer the promise of smaller antennas for the same amount of gain. For example Ka Band frequencies and above are getting interest from both the antenna size aspect as well as the frequency congestion aspect. The antenna diameter decreases linearly with transmission frequency for the same beamwidth. The drawback of using the higher frequencies is that they are more susceptable to attentuation and distortion by intervening material such as water vapor / droplets in the atmosphere. Moreover, power amplifier efficiency is generally lower at higher frequencies. Increasing $\mathrm{Ka}$ band power amplifier efficiency is an active area of research (Schellenberg 1995).

Finally, in a number of microsatellite missions, real time access to the data may not be critical. In these missions, power scheduling techniques can be used to require the duty cycle of the satellite to ground link to be rather low. Such store and forward systems will then offer relatively high data rates for short periods of time. In these periods of time, most of the onboard power can be directed towards the communications package, supporting the downlink of the required data. The cost of this technique is that more onboard data storage is required and that instruments may have to be powered down during data transfer.

\section{UNITIZED POWER AND PROPULSION SYSTEM}

A powerful illustration of the benefits of the integration of propulsion and power is the reversible Unitized Regenerative Fuel Cell (URFC) design by Hamilton Standard, and shown in Figure 3. A number of papers have been published describing the operation of the regenerative system, with cell operation as an electrolysis and fuel cell (McElroy 1994, Butler 1995). The working fluid of the system is water, a safe, clean, storable fluid. The central unit is a $\mathrm{H}_{2} / \mathrm{O}_{2}$ solid proton exchange $\left(\mathrm{SPE}^{\circledast}\right)$ URFC design, based on the proton exchange membrane as sole electrolyte. This sulfonic acid membrane electrolyte is fashioned into electrochemical cells by bonding catalyst electrodes to both faces of the membrane.

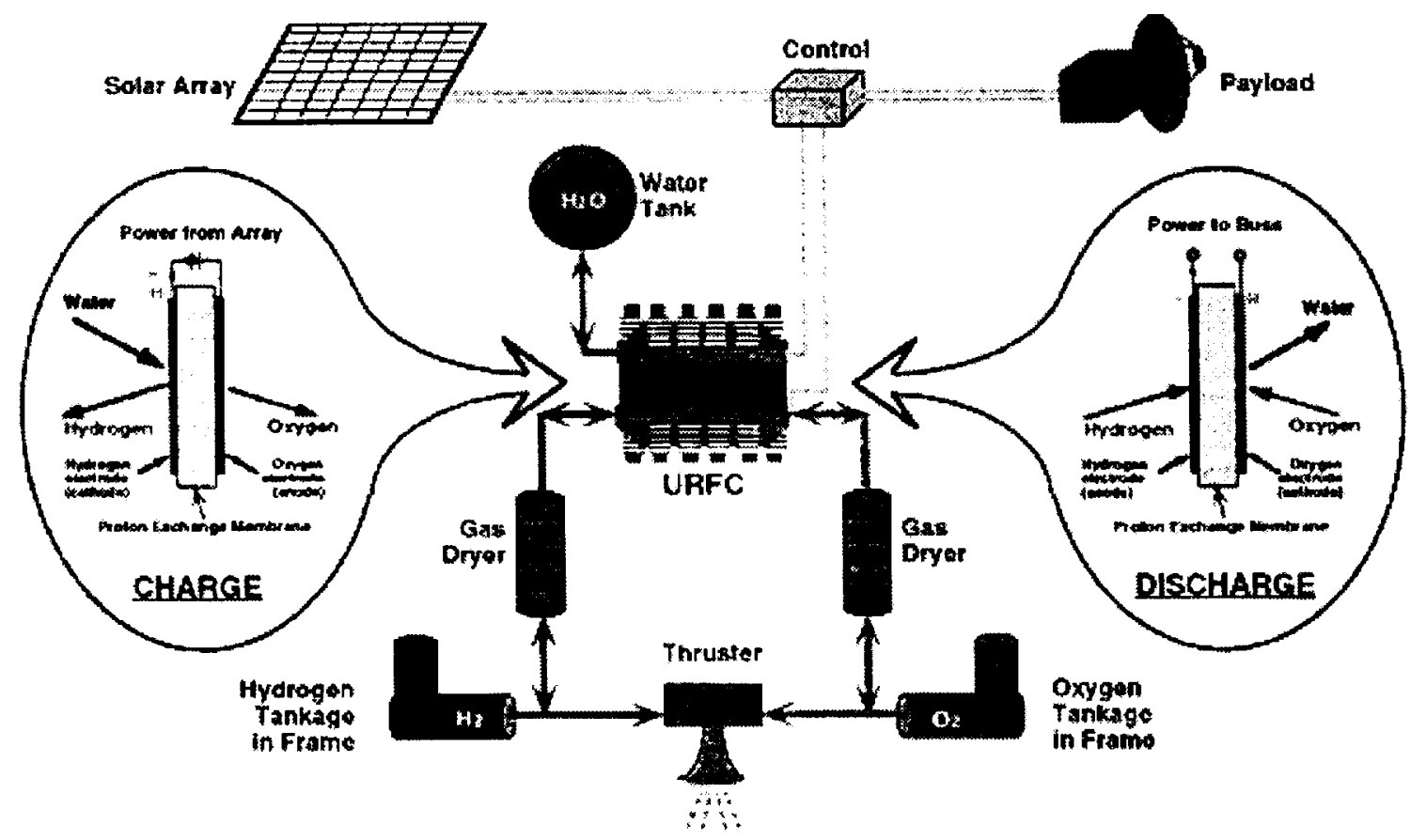

Figure 3. Integrated Modular Propulsion and Regenerative Electro-Energy Storage System. 
A single electrolysis cell consists of a water feed chamber, a water permeable membrane, a hydrogen chamber, a SPE membrane, an oxygen chamber, an electrochemical hydrogen pump, and electrical insulators on both end plates. Hydrogen and oxygen are produced on either side of the SPE membrane with the application of DC power. The water feed chamber is separated from the hydrogen gas chamber by water permeable membranes which allow osmotic water transport into the hydrogen chamber. Because water is being consumed to produce propellants, a water gradient is established across the water feed barrier and more water from the storage tank enters the cell. An electrochemical hydrogen pump, drawing a few milliwatts of power, assures that no hydrogen builds up in the water feed chamber.

Surplus power from the photovoltaic array, not needed for payload and housekeeping functions, is supplied to the URFC. Water electrolysis inside the URFC generates hydrogen and oxygen. These gases are stored inside spacecraft structural components lined with lightweight bladder liners providing a permeation barrier for gas storage. State of the art hydrogen bladder technology developed at Lawrence Livermore National Laboratories safely allows such storage (Butler 1995).

Several spacecraft functions can be serviced by the stored gases. The cold gases can be used for attitude control (ACS) and fine pointing, by providing low thrust, small impulse bit pulses through small cold gas thrusters. The gases can also be used as propellants in gaseous bi-propellant thrusters for primary propulsion or larger delta- $\mathrm{V}$ maneuvers. This dual mode potential allows replacement of conventional combinations of hydrazine/cold gas systems at a significant weight and volume savings. For periods during which the solar arrays can not provide power, the URFC, operating as a fuel cell, produces DC power and water, returning the water to its thin-walled, light weight storage container. For many missions, the fuel cell by itself compares favorably to state of the art batteries in terms of power vs. weight ratio. Integration with the propulsion system provides additional reduction in spacecraft weight and volume.

\section{INTEGRATED POWER AND ATTITUDE CONTROL}

One opportunity which should be explored during spacecraft design phases is to utilize a flywheel system for both energy storage and spacecraft control. By appropriate positioning and control of flywheels, a net torque can be placed on the spacecraft by a combination of spin up/spin-down of the flywheels used for energy storage (Christopher and Beach 1997). This Integrated Power and Attitude Control System (IPACS), shown in Figure 4, stores kinetic energy in the motion of the flywheel, and utilizes the angular momentum of the rotating flywheel for spacecraft attitude control, such has historically been done with reaction wheels (control moment gyros).

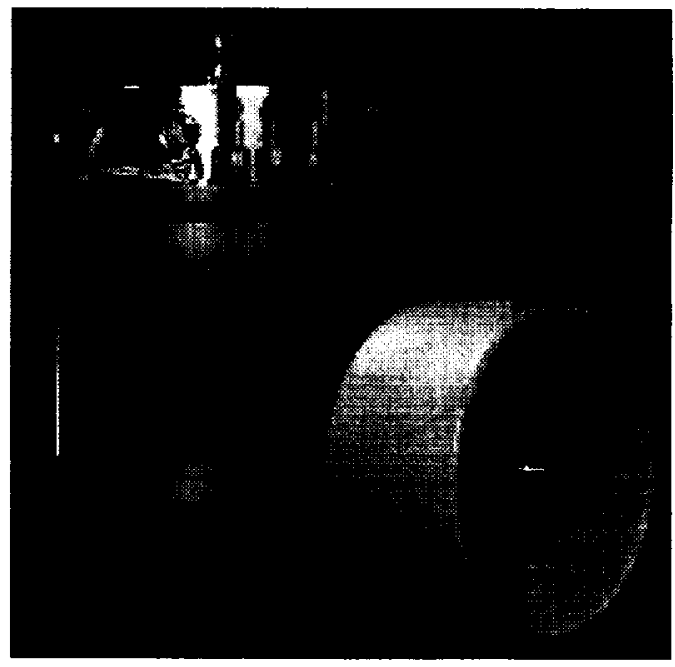

Figure 4. Integrated Power and Attitude Control System. 
Developments in flywheel design that have made the IPACS possible are: 1. the use of magnetic bearings which reduce friction losses, increase lifetime, improve balancing, and reduce noise effects (vibrations) that can introduce pointing jitter and affect sensor instruments, and 2. the use of composites which made it possible to concentrate the mass on the edge of the flywheel for a maximum of energy storage with a minimum of mass.

The main advantages of the magnetic bearing based IPACS system are: 1. the high energy storage roundtrip efficiency $(85-90 \%)$ as compared to batteries $(75-78 \%)$ or fuel cells (50\%), which saves energy; 2 . the small volume required; 3 . the long life which increases mission life and reduces cost; 4. increase in specific energy, which reduces mass; 5 . the large control torques which reduces the need for propulsion systems; and 6. the reduction in vibrations which improved instrument performance. Maximum benefits are expected for LEO. A Japanese on-orbit experiment, named Magnetic Bearing Flywheel Experiment System (MABES) showed (Nakajima 1990) that magnetic bearings exhibited sufficient stability in a microgravity environment for spacecraft attitude control.

\section{INTEGRATED PAYLOAD, COMMUNICATION, AND PROPULSION}

For a number a scientific experiments, cryogenic dewars carry liquid helium to cool the instrumentation to a temperature where noise levels are low enough to obtain desired sensitivity. Missions planned that include cryogenic helium are the Gravity Probe B (GP-B), STEP, and GOCE. These cryogenic dewars can be concurrently used to increase the sensitivity of an onboard communications or telemetry receiver. One of the most important effects on the signal to noise ratio (SNR) of a communications link is the noise temperature of the receiver's low noise amplifier (LNA). If the LNA is cooled to cryogenic temperatures, a few dB increase SNR can be obtained, resulting in a significant increase in data rate, decrease in antenna size, or both. In most cases, this improvement is not sufficient to warrant a dedicated cryogenic system, but leveraging cryocooling of an available system has many possibilities to make it worthwhile.

In a cryogenic dewar, even with the best insulation, boil-off of the liquid helium will occur. Leaking gaseous helium can cause an undesirable, constant, microscopic thrust, which can be used to the spacecrafts advantage. Depending on the orbit and solar activity, some drag will occur on the spacecraft, which causes a microgravity environment. To make the spacecraft drag free, the boiloff helium can be used to compensate for the drag. Because the boil-off is extremely low with good insulation, the available gaseous helium may not be enough to compensate for the drag encountered. In that case the insulation needs to be reduced until a level of boil-off occurs sufficient to make-up for the predicted drag. However, this will also reduce the experiment lifetime.

As an example, to make up for the average drag of approximately $1 \mathrm{mN}$ encountered by the GP-B, helium thrusters are designed to operate at a thrust range from $73 \mu \mathrm{N}$ to $30 \mathrm{mN}$. The comparable Isp's are $150 \mathrm{~s}$ and $135 \mathrm{~s}$. These thrust levels are in the desirable range for micropropulsion applications.

\section{SUMMARY}

In order to reduce mission costs, spacecraft have to be designed smaller and more efficient. A reduction in spacecraft size can only be accomplished with size reductions in systems and subsystems. Several subsystems, such as sensors, electronics, and communications lend themselves for miniaturizing. However, propulsion systems, due to the usually large required consumables, are 
harder to miniaturize. One approach to reduce weight and volume is to combine hardware for several spacecraft systems, such that the same hardware performs several subsystem functions.

State-of-the-art in the power, propulsion, and communications area as it relates to small and miniature components have been described. Technology directions to obtain lighter, less expensive systems have been highlighted. Individual approaches to reduce volume and weight of each of those systems have been discussed.

Several integrated systems and subsystems have been discussed. An integration of primary and ACS propulsion with power and spacecraft structure has been described. This system which is based on water electrolysis and fuel cell technology for bipropellant thrust and energy storage utilizes state-of-the-art membrane technology for propellant storage inside spacecraft structural components.

Flywheels have been discussed as a means of combining high specific energy storage with accurate ACS functions, primarily for LEO spacecraft. The utilization of cryogenic boil-off for drag makeup thrusters has been discussed.

\section{REFERENCES}

Berrou, C., A. Glavieux, and P. Thitimajshima, Near Shannon Limit Error-Correcting Coding and Decoding: Turbo Codes, ICC, pp 1064-1070 (1993).

Butler, L.B., Integrated Modular Propulsion and Regenerative Electro-Energy Storage System (IMPRESS), Hamilton Standard Proposal to New Millennium Program, (1995).

CCSDS 101.0-B-3: Telemetry Channel Coding. Blue Book. Issue 3. This recommendation has been adopted as ISO 11754:1994. Available at http://www.ccsds.org (1992).

Christopher, D.A., and R. Beach, Flywheel Technology Development Program for Aerospace Applications, IEEE National Aerospace and Electronics Conf., Dayton, OH, Vol. 2 pp. 602-608 (1997)

de Groot, W.A., Propulsion Options for Primary Thrust and Attitude Control of Microsatellites, COSPAR Colloquium on Scientific Microsatellites, Tainan, Taiwan (1997).

Gambles, J. W., A Path Towards Low-Cost Rad-Tolerant CMOS, $6^{\text {th }}$ NASA Symposium on VLSI Design (1997).

Janson, S., Chemical and Electric Micropropulsion Concepts for Nanosatellites, Paper AIAA-94-2998, $30^{\text {th }}$ Joint Propulsion Conference, Indianapolis, IN (1994).

McElroy, J., Unitized regenerative fuel cell storage system for aircraft and orbital applications, UTC Hamilton Standard Div., Rept. BD94-02 (1994).

Myers, R.M., Oleson, S.R., Curran, F.M., and Schneider, S.J., Chemical and Electrical Propulsion Options for Small Satellites, Proc. $8^{\text {th }}$ AIAA Utah State University Conference on Small Satellites (1994).

Pellerin, A., Are You Talking Batteries, Electric and Hybrid Vehicle Technology (1996).

Power Computing Solutions, Inc., Energy Source Technology Survey for High Altitude UAV, Final Report, Contract NAS2-96011, NASA Ames Research Center (1997).

Schellenberg, J.M. A High-Voltage, Ka-Band Power MMIC With $41 \%$ Efficiency, Proc. of the 17 th Annual GaAs IC Symposium, 95CH35851, Oct. 29 - Nov. 1, 1995, pp. 284-287.

Warshay ,M. et al., The NASA Fuel Cell Upgrade Program for the Space Shuttle Orbiter, IECEC (1997).

Yeh, P. and W. H. Miller, A Real Time Lossless Data Compression Technology for Remote Sensing and Other Applications, ISCAS-95 (1995). 



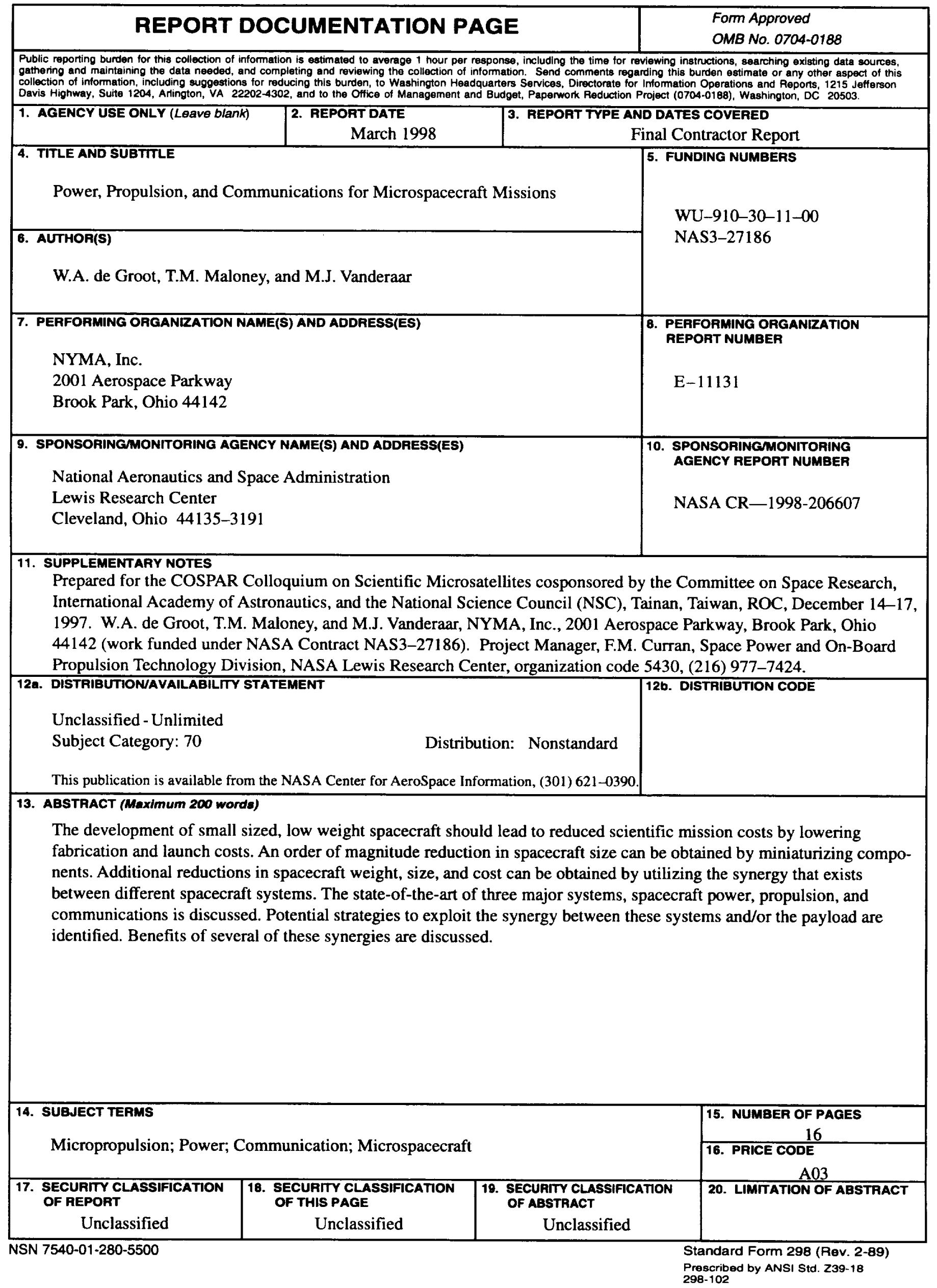

